\title{
Risk Factors and Maternal Outcome of Secondary Post Partum Haemorrhage in Rangpur Medical College Hospital. - A one year study
}

\author{
HASINA FERDOUSY ${ }^{1}$, FERDOUSI SULTANA ${ }^{2}$, MST. KAMRUN NAHAER ${ }^{3}$, \\ MST. MOON MOON BEGUM ${ }^{4}$, MST. MAHFUZA BEGUM ${ }^{5}$
}

\begin{abstract}
:
Background: Post partum haemorrhage (PPH) is one of the most common causes of maternal mortality worldwide. Primary PPH (which occurs within 24 hours of delivery) has been studied a lot. But data regarding secondary PPH (which occurs 24 hours after delivery upto to 6 weeks post partum) is sparse. Our aim was to find out the risk factors and maternal outcome of secondary PPH.
\end{abstract}

Materials and Methods: A cross sectional analytic study of 32 cases admitted with secondary PPH in Gynae and Obstetric department of Rangpur Medical College Hospital during 1 year study period was carried out.

Result: Frequency of secondary PPH was $0.58 \%$. Mean age of the patient was $25.23 \pm 2.79$ years; 22(69\%) patients were multi para; 17 (53\%) patients had education up to primary level. Maximum patients [18 (56\%)] were from low socio economic status. Mean time of presentation was $13.5 \pm 2.78$ days after delivery; $14(44 \%)$ patients delivered vaginally and $18(56 \%)$ patients delivered by caesarean section. Most of the vaginal delivery $9(28 \%)$ were conducted by untrained dai or other family member. Among 32 patients, 31 were referred from outside the Hospital. Retained bits of placenta was the leading cause $(15,47 \%)$ and caesarean wound dehiscence was the second cause (13,41\%); 13 (40\%) patients had fever on presentation. All were anemic with mean hemoglobin concentration $7.4 \pm 1.4 \mathrm{gm}$ and 24 (75\%) of them required blood transfusion. Four patients was in shock. Antibiotic was given to all patients. DE\&C was done in $15(47 \%)$ cases and laparotomy followed by total abdominal hysterectomy was done in 12 cases and repair in 1 case. Among 15 patients who underwent surgical evacuation there was histological evidence of placental tissue in only 6(40\%) patients.

Conclusion: In present study retained bits of placenta and caesarean wound dehiscence are found as main cause of secondary postpartum hemorrhage So care should be taken during active management of third stage of labour (AMTSL). Choosing appropriate suture material, maintaining personal hygine of patient and sterility of operation theate, using appropriate antibiotic to combat microbials and last but not list improving skillness of surgeon are the key to reduce the rate of secondary PPH.

Keyword: AMTSL, Secondary PPH, Retained bits of placenta

Introduction:

Post partum hemorrhage represent a serious problem for women and obstetricians ${ }^{1}$. About $31 \%$ of maternal death in Bangladesh are due to haemorrhage ${ }^{2}$. Because of its association with hemorrhagic shock and predisposition to disseminated coagulopathy it is a leading cause of maternal death world wide ${ }^{3}$. Secondary PPH is

1. Hasina Ferdousy, Junior Consultant, Dept. of Obs \& Gynae, Rangpur Medical College Hospital, Rangpur. Email address - dr.hasina.ferdousy@gmail.com, mob no - 01716-066908

2. Ferdousi Sultana, Professor \& Head of the Dept. of Obs \& Gynae, Rangpur Medical College \& Hospital, Rangpur.

3. Mst. Kamrun Nahaer, Associate Professor, Dept. of Obs \& Gynae, Rangpur Medical College \& Hospital, Rangpur

4. Mst. Moon Moon Begum, Resident Surgeon, Dept. of Obs \& Gynae, Rangpur Medical College Hospital, Rangpur

5. Mst. Mahfuza Begum, Medical Officer, Eye OPD, Rangpur Medical College Hospital, Rangpur

Address of Correspondence: Hasina Ferdousy, Junior Consultant, Dept. of Obs \& Gynae, Rangpur Medical College Hospital, Rangpur. Email address - dr.hasina.ferdousy@gmail.com, mob no - 01716-066908 
defined as excessive vaginal bleeding form 24 hours after delivery upto 6 weeks post partum ${ }^{4}$. The jeopardy of $\mathrm{PPH}$ is rising with the secondary form of $\mathrm{PPH}$ which occur when women are already discharged home. Unlike the definition of primary $\mathrm{PPH}$ there is no clear or standard definition for quantity of blood loss associated with secondary $\mathrm{PPH}$. It is a clinical diagnosis of exclusion which may present with increased Lochia to massive bleeding after birth. The etiology of secondary PPH is diverse and management is dependent on identifying the cause and tailoring treatment appropriately. The common cause of secondary PPH include retained product of conception and/or infection and rarer causes include dehiscence of cesarean section scar, choriocarcinoma, haematological disorders such as thrombocytopenia, and Von Wille brands disease. While there is plenty of data available in world literature regarding primary $\mathrm{PPH}$, secondary $\mathrm{PPH}$ has not been studied with similar zeal. However with declininig maternal mortality rate in many parts of the world, interest in and attention to maternal morbidity due to secondary PPH is increasing. We aimed to find out the incidence, causes and outcome of patients who presented to our hospital with secondary $\mathrm{PPH}$ in a particular time.

\section{Methods:}

A cross sectional study was conducted on all patients admitted in Rangpur Medical College Hospital with a diagnosis of secondary PPH over a period of one year between January 2016 to December 2016 in the Department of Obstetrics \& Gynaecology. Information regarding socio demographic profile, previous obstetric history, mode of delivery, history of manual removal of placenta and primary PPH, place of delivery, day of presentation after delivery, total Hospital stay, treatment given and final outcome - discharge or death was recorded. Patients in whom case records were incomplete and lacked any of the information we required, were excluded. Data was collected by history taking, physical examination, required investigations and from the information on mode of treatment. Informed consent was obtained. Privacy and confidentiality of the patient was maintained. Ethical permission was blamed from the institution.

\section{Result:}

Out of total 5448 admission in hospital due to obstetric causes in one year, 535 patients were admitted because of PPH. Of them 32 were due to secondary $\mathrm{PPH}$. So incidence of secondary PPH in the present study is $0.58 \%$. (Table 1 ).
Table-I

Frequency of secondary PPH

\begin{tabular}{lcc}
\hline & Number & $\begin{array}{c}\text { Number with } \\
\text { secondary PPH } \\
\text { (percentage) }\end{array}$ \\
\hline $\begin{array}{l}\text { Total hospital admission } \\
\text { for obstetric causes }\end{array}$ & 5448 & $32(0.58 \%)$ \\
Total admission for PPH & 535 & $32(5.9 \%)$ \\
\hline
\end{tabular}

Mean age of the patient is $25.23 \pm 2.79$ years. Among 32 patients $20(63 \%)$ were found between the age group 20-25 years, 7 (22\%) were between 25-30 years, $4(12 \%)$ between $30-35$ years and $1(3 \%)>35$ years (Table 2 ). So age of the patients ranges from 20-40 years.

Maximum patients $22(69 \%)$ were multi para and $10(31 \%)$ were primi para. Five $(15 \%)$ patients were illiterate, 17(53\%) completed primary education, 7 (22\%) had secondary education, 2(6\%) had higher secondary education. $1(3 \%)$ patient had competed graduation. Most of them 18(56\%) were from low socio economic status. $10(31 \%)$ were from lower middleclass and only $4(12 \%)$ were from upper middleclass.(Table 2$)$.

Table-II

Distribution of study subject according to socio demographic profile.

\begin{tabular}{|c|c|c|}
\hline Variables & $\begin{array}{c}\text { Number of } \\
\text { patients } n=32\end{array}$ & Percentage \\
\hline Age group (Means $\pm S D$ ) & $25.23 \pm 2.79$ & \\
\hline \multicolumn{3}{|l|}{ years } \\
\hline $20-25$ & 20 & 63 \\
\hline $25-30$ & 7 & 22 \\
\hline $30-35$ & 4 & 12 \\
\hline$>35$ & 1 & 3 \\
\hline \multicolumn{3}{|l|}{ Parity } \\
\hline Primi para & 10 & 31 \\
\hline Multi para & 22 & 69 \\
\hline \multicolumn{3}{|l|}{ Level of education } \\
\hline Illiterate & 5 & 15 \\
\hline Primary & 17 & 53 \\
\hline Secondary & 7 & 21 \\
\hline Higher secondary & 2 & 6 \\
\hline Graduate and post graduate & 1 & 3 \\
\hline \multicolumn{3}{|l|}{ Socio economic status } \\
\hline $\begin{array}{l}\text { Low (monthly income } \\
\text { taka }<5000 \text { ) }\end{array}$ & 18 & 56 \\
\hline $\begin{array}{l}\text { Lower middle (monthly income } \\
\text { taka } 5000-10,000 \text { ) }\end{array}$ & 10 & 31 \\
\hline $\begin{array}{l}\text { Upper middle (monthly income } \\
\text { taka } 10,000-30,000 \text { ) }\end{array}$ & 4 & 12 \\
\hline $\begin{array}{l}\text { High monthly income } \\
\text { taka }>30,000\end{array}$ & 0 & 0 \\
\hline
\end{tabular}

Mean time of presentation after delivery was $13.5 \pm 2.78$ days. In $3(9 \%)$ cases secondary $\mathrm{PPH}$ 
occur within $1^{\text {st }}$ week, in $15(47 \%)$ cases during $2^{\text {nd }}$ weeks, in $11(34 \%)$ cases during $3^{\text {rd }}$ week and $3(9 \%)$ cases during $4^{\text {th }}$ weeks (Table 3 ).

Table-III

Distribution of study subject according to delivery related information of current pregnancy.

\begin{tabular}{lcc}
\hline Mode of delivery & Number & Percentage \\
\hline Vaginal delivery & 14 & 44 \\
$\quad$ Caesarean section & 18 & 56 \\
$\begin{array}{l}\text { Vaginal delivery conducted by } \\
\text { Untrained dai/ other family }\end{array}$ & 9 & 28 \\
$\quad$ member & 5 & 15 \\
$\quad$ Medical personnel & & \\
Place of delivery & 31 & 96 \\
$\quad$ Outside the Hospital & 1 & 3 \\
$\quad$ Inside the Hospital & $13.5 \pm 2.78$ & \\
Time of presentation & & \\
(Means \pm SD) days & 3 & 9 \\
Within 7 days & 18 & 56 \\
$\quad$ 8-14 & 8 & 25 \\
15-21 & 3 & 9 \\
22-28 & 3 & 9 \\
Manual removal of placenta & 4 & 12 \\
Primary PPH history &
\end{tabular}

Fourteen (44\%) patients delivered vaginaly and $18(56 \%)$ patients delivered by caesarean section. Most of $9(28 \%)$ these vaginal delivery were conducted by untrained dai or other family member and remaining $5(15 \%)$ by other medical personnel. Except 1, 31 cases were referred from outside the hospital.

History of manual removal of placenta was found in $3(9 \%)$ cases while to $4(12 \%)$ had history of primary PPH. (Table 3)

Thirteen (40\%) patients had fever on presentation. Mean hemoglobin concentration was $7.4 \pm 1.4 \mathrm{gm} / \mathrm{dl}$. $7(21 \%)$ were mildly anemic $15(46 \%)$ were moderately anemic and $10(31 \%)$ were severely anemic. $4(12 \%)$ was in shock $4(12 \%)$ uterine tenderness with foul smelling lochia (Table 4).

\section{Table-IV}

Distribution of study subject according to clinical presentation

\begin{tabular}{lcc}
\hline & number & Percentage \\
\hline Fever & 13 & 40 \\
Haemoglobin & $7.4 \pm 1.4$ & \\
(mean \pm SD) gram/dl & & \\
$\quad$ Mild (8-10gm) & 7 & 21 \\
$\quad$ Moderate (6-8gm) & 15 & 46 \\
$\quad$ Severe (<6gm) & 10 & 31 \\
Shock & 4 & 12 \\
Uterine tenderness with & 4 & 12 \\
foul smelling lochia & & \\
\hline
\end{tabular}

Retained bits of placenta was the leading cause in $15(47 \%)$ cases and caesarean wound dehiscence was the $2^{\text {nd }}$ common cause found in $13(41 \%)$ cases. In other 4 cases, cause was endometritis (Table 5). No placental tissue was found on ultrasonography and they responded well to conservative approach.

Table-V

Distribution of study subject according to causes of secondary $\mathrm{PPH}$

\begin{tabular}{lcc}
\hline Cause & No. & Percentage \\
\hline Retained bits of placenta & 15 & $47 \%$ \\
Caeserean wound dehiscence & 13 & $41 \%$ \\
Others & 4 & $30 \%$ \\
\hline
\end{tabular}

Antibiotic was given to all patients $D, E \& C$ was done in $15(47 \%)$ cases due to USG finding of retained bits of placenta; $24(75 \%)$ patients required blood transfusion ranging from 1 unit -5 unit per patient as per requirement. Laparotomy was done in $13(41 \%)$ cases due to torrential haemorrhage not responding to conservative management and caesarean wound dehiscence was found with ragged infected margin. So total abdominal hysterectomy done for life saving purpose in 12 cases and repair done in 1 case. Three patients required inotropic support (Table 6). Among 15 patients who underwent surgical evacuation there was histological evidence of placenta tissue in only $6(40 \%)$ patients. Two report were missing and others were reported as degenerative decidua or endometritis or organized blood clots (Table 6). Total hospital stay was 5-25 days varying from patient to patient. Post operative wound infection occur in 5 cases and there was no mortality. Though ultra sonogram was done in all cases ; in fifteen cases retained product of conception was seen but there was less relationship with histopathology (table 7).

Table-VI

Intervention required both medical and surgical

\begin{tabular}{lcc}
\hline Intervention & No & Percentage \\
\hline D, E \& C & 15 & 47 \\
Laparotomy & 13 & 41 \\
Blood transfusion & 24 & 75 \\
Inotropic support & 4 & 12 \\
Antibiotic & 32 & 100 \\
\hline
\end{tabular}


Table-VII

correlation between sonographic findings and histology

\begin{tabular}{|c|c|c|c|c|}
\hline \multirow[t]{3}{*}{ Sonography } & \multicolumn{4}{|c|}{ Retained placental tissue seen on histology } \\
\hline & \multicolumn{2}{|c|}{ yes } & \multicolumn{2}{|c|}{ No } \\
\hline & No. & $\%$ & No. & $\%$ \\
\hline Retained placental tissue seen in 15 cases & 6 & 40 & 9 & 60 \\
\hline
\end{tabular}

\section{Discussion:}

Post partum haemorrhage is the leading cause of maternal mortality. All women who carry pregnancy beyond 20 weeks gestation are at risk for PPH and its sequilae ${ }^{7}$. In our study period total 5448 patients were admitted due to obstetric causes and among them number of secondary PPH was 32 . Frequency of secondary PPH in this study is $0.58 \%$. The percentage is significant and it is consistent with other study. The study by Rome ${ }^{8}$ showed the incidence of $1.29 \%$ and Hoveyda and Mackenzie ${ }^{9}$ reported an incidence of $0.8 \%$. A study done in Africa revealed that about one third of the total PPH cases was secondary $\mathrm{PPH}^{10}$. It is high due to poverty lack of awareness and late intervention in Africa. Similar study done in Nepal revealed secondary PPH was the cause of about $0.32 \%$ cases of $\mathrm{PPH}{ }^{11}$.

Maximum patients in this study was within age group 20-25 years. Mean age of our patient was $25.23 \pm$ 2.79 years which does not corroborates with previous study where age $>35$ years was found to be associated with increased risk of secondary $\mathrm{PPH}^{12,13}$. This is due to early age of marriage in our country and by this age they become multipara.

In this study maximum $22(69 \%)$ patients were multi para which was similar to other study ${ }^{12}$. But we cannot conclude that multiparity is a risk factor. Yet indirectly we can say multiparity as a risk factor. Due to previous experience, their delivery is supervised by untrained traditional birth attendants or family member at home which may be associated with high incidence of poor and delayed management of third stage of labour leading to more chance of retained bits of placenta. Besides most of them are poor, malnourished, anemic. So more susceptible to infection and $\mathrm{PPH}$.

Most of the patients $17(53 \%)$ had primary education. Out of 32 patients illiteracy constituted 5(15\%); $7(21 \%)$ passed secondary, $2(6 \%)$ higher secondary and only $1(3 \%)$ had completed graduation. Education is more important for awareness building about health, taking rapid decision for taking necessary steps and understanding importance of delivery by trained personnel or in well equipped Hospital ${ }^{14}$.

Maximum 18(56\%) were from low socio economic status. $10(31 \%)$ from lower middle, 4(12\%)from upper middle and none from affluent society. The low income group delays to take decision for seeking care and transfer the patient to appropriate center due to lake of money and awareness. So timely interference is deferred and risk of patients is increased. The risk also increased in poor due to preexisting malnutrition, anaemia and unsupervised home delivery ${ }^{15}$.

About $18(56 \%)$ patients with secondary PPH were delivered by caesarean section and 14(44\%) were vaginally. This can be explained by rising rate of caesarean section is recent trend. According to Bangladesh maternal mortality survey 2010 , the rate of caesarean section is $17.1 \%$ which is alarming. This result is different from study done by waseeqa et all and Thangappah ${ }^{5,6}$ where maximum patients had vaginal delivery. Most of the vaginal delivery $9(28 \%)$ were conducted by untrained dai or other family member which indicates the role of unskilled and unhealthy delivery practice as a risk factor for secondary PPH. The risk of PPH is much higher for women undergoing caesarean section particularly in developing countries where the majority of operation are carried out as an emergency procedure where proper asepsis is not taken and quality suture may not be used. Out of 32,31 cases both vaginal delivery and caesarean section were referred from outside. Overall incidence is very low in the Hospital because environment of the labour room is patient friendly and active management of third stage of labour (AMTSL) is done in all cases. Upmost asepsis is maintained and quality suture material is used during cesarean section. Indirectly we might conclude that skilled supervision of delivery and labour including AMTSL and maintaining asepsis decrease risk of secondary $\mathrm{PPH}$. AMTSL has been followed as a strategy to prevent $\mathrm{PPH}$ including secondary $\mathrm{PPH}^{11}$. 
Maximum patients $18(56 \%)$ present within 8-14 days of delivery which is similar to other study ${ }^{5}$.

History of manual removal of placenta and primary $\mathrm{PPH}$ was found in $3(9 \%)$ and $4(12 \%)$ cases. These two risk factors have been associated with secondary $\mathrm{PPH}$ due to infection and all steps should be taken to prevent these ${ }^{16}$.

Thirteen (40\%) patients presented with fever and $4(12 \%)$ with other signs of infection like uterine tenderness and foul smelling lochia. Bleeding varied with each patient. Mean hemoglobin concentration was $7.4 \pm 1.4 \mathrm{gm} / \mathrm{dl} .7(21 \%)$ were mildly anemic, $15(47 \%)$ were moderately and $10(31 \%)$ were severely anemic and they need blood transfusion accordingly $4(12 \%)$ were in hyvolumic shock at presentation and required resuscitation and inotropic support. This signifies amount of bleeding vary greatly.

In $15(47 \%)$ patients $\mathrm{D}, \mathrm{E} \& \mathrm{C}$ was done due to retained bits of placenta which is consistent with previous study ${ }^{5,16} .13(41 \%)$ patients needed Laparotomy and caesarean wound dehiscence was found as the cause. In cases where heavy bleeding occurs 2-3 weeks following caesarean section, either non healing of uterine incision or dehiscence of the scar following infection should be thought of ${ }^{17}$. All the cases were done on emergency and poor quality suture material was found to be used on Laparotomy. Repair could be done in one case and total abdominal hysterectomy was done in 12 cases due to friable ragged infected margin.

In 4 cases no active intervention required. They responded well to conservative approach by parenteral antibiotic, antiseptic vaginal wash and blood transfusion and discharged after few days.

All patient underwent ultrasonography to confirm the diagnosis, avoid litigation and to boostup the patients psychologically. But the use of ultrasonography in diagnosing the cause of PPH is controversial as organized clot are difficult to differentiate from retained products. In our analysis only in $6(40 \%)$ cases the ultrasound diagnosis of retained product was confirmed by histology. Our experience was similar to that of Hoveyda F. and Mackenzie. ${ }^{12}$

Mortality is nil. Predominant maternal mortality is caused by primary PPH. Although morbidity in secondary PPH is significant it usually does not lead to death if such patient are properly managed.

\section{Conclusion and Recommendation}

Though the frequency of secondary PPH is low, it is one of the cause of maternal morbidity and sufferings. Therapeutic management is close to primary PPH and requires coordination and multidisciplinary care aiming the immediate hemodynamic stabilization of the patient followed by investigation and treatment of specific cause of haemorrhage. In our study retained product of conception is found as common cause but secondary PPH due to caesarean wound dehiscence also found in a significant number of cases. So care giver should be well trained so that they can manage third stage properly AMTSL should be a routine practice in all cases for management of $3^{\text {rd }}$ stage of labour. Asepsis should be maintained in all aspect, quality suture material should be used and appropriate antibiotic during caesarean section should be given. Last but not the least surgeon must be skilled. At the same time women empowerment, improving their health and educational status will also reduce the morbidity from secondary $\mathrm{PPH}$.

\section{Reference:}

1. Pavol Zubor, Karol Kajo et all. Recurrent secondary PPH due to placenta site vessel sub involution and local uterine tissue coagulopathy. BMC. Pregnancy and child birth 2014.

2. NIPORT,USAIDS, UNFPA, Australian Govt, Bangladesh maternal mortality survey 2010.

3. Carroli G, Cuesta C, Abalos E, Gulmezogluam, Epidemiology of PPH: a systemic Review. Best pract. Res. Clin. Obstet. Gynaecol-2008, 22:999-1012.10-1016/ J.b. pobgyn. 2008.08004. Review article pubmet Goole scholar.

4. Thompson W, Harper M. Postpartum haemorrhage and abnormalities of the third stage labour. In chamberlain G. Steer. P. edr. Turn bulls obs. $3^{\text {rd }}$. edn. Edenburgh.

5. Thangaappah Radha Bai Prabhu. Institute of Obs \& Gynae and Govt. Hos. For women and children, Chennai. 600008. Obstet Gynecol ind. V 54 NO 3; May/June 2004.

6. Waseeqa Nigeen, w Mariya Farooq $m$ et all. Secondary PPH in tertiary care hosp. on North India: a retrospective analyses. International Journal of Reproduction, Contraception, Obstetrics and Gynecology. (IJRCOG 2017, vol $6(2)$ 
7. J R Smith (MD), Barbara G. Brennan (MD) et all Post Partum Haemorrhage update. Mar01, 2016, Medscape Journal. 532-36

8. Rome RM. Secondary PPH. Br. J obstet. Gynecol. 1975; 82: 289-92.

9. Hoveyda F. Mackenzie TZ. Secondary PPH: Incidence, morbidity and current management. Br. J obstet Gynecol 2001; 108. 927.30.

10. A Jenifuja KO, Adepiti CA, Ogynniyi SO, PPH in a teaching hospital in Nigeria: a 5 years experience, African Health science 2010; 20(1): 71-4.

11. Dongol AS, Shres tha. A, Chawla CD. Post partum haemorrhage: prevalence, morbidity and management pattern in Dhulikhel Hosp. Kathm and Univ med J. (KUMJ) 2010; 8(30): 212-5.

12. Jaleel $\mathrm{R}, \mathrm{Khan}$. A. PPH - a risk factor analysis. Mymensing med. J. 2010; 19(2) 282-9.
13. Debast - Legrand A, Riviere O, Dossov M, Vendittelli F, Risk factors for severe secondary PPH: A Historical cohort study Birth 2015; 42(3): 235-41.

14. Nila T.A. a study of 100 cases of retaine placenta in Mymensing Medical Collage Hospital - BCPS Dissertation 2007, 89-94.

15. DAS SR, Sultana N, Akhter S Khan. Incidence causes and management of retained placenta admitted cases in inpatient department. BCPS dissertation 2015

16. Debost, Legrand A, Dechelothe P Lemery D, Vendittelli F. Severe secondary PPH: a historical cohort. Birth 2015; 42(2): 149-55.

17. Nandas, Singhat $S$, Sharma $D$ et al. Nonunion of uterine incision: A rare cause of secondary PPH: A report of 2 cases: Aust. NZJ. Obstet Gynecol 1997;37:475-6. 